Supporting Information

\title{
Graphene oxide membranes for isotopic water mixture filtration: preparation, physicochemical characterization, and performance assessment
}

\author{
Aida Mohammadi ${ }^{1}$, Mark R. Daymond ${ }^{2}$, Aristides Docoslis ${ }^{1 *}$
}

1. Department of Chemical Engineering, Queen's University, Kingston, Ontario, K7L 3N6.

2. Department of Mechanical and Materials Engineering, Queen's University, Kingston, Ontario, K7L 3N6.

*Corresponding author: Aristides Docoslis, Email: docoslis@queensu.ca

Total pages: 10 (S1-S10)

Table of contents:

\section{Figures}

Figure S1. SEM images of nanoplatelets on a silicon substrate (a) GO-1 and (b) GO-2.

Figure S2. Flake size distribution for (a) GO-1 and (b) GO-2 dispersion, respectively.

Figure S3. AFM images of $(a, b)$ a typical GO-1 sheet platelet and its height profiles across the overlap (yellow line), (c, d) a typical GO-2 sheet platelet and its height profiles across the overlap (yellow line).

Figure S4. (a) SEM image showing the cross-section of a membrane prepared with larger lateral platelet size dispersion $(\mathrm{Vg}=25 \mathrm{~mL}$ and $\mathrm{Cg}=1 \mathrm{mg} / \mathrm{mL})$ and (b) XRD pattern for the prepared $\mathrm{GO}$ membrane.

Figure S5. XRD patterns for the GO membranes prepared with $\mathrm{Cg}=0.55 \mathrm{mg} / \mathrm{mL}$.

Figure S6. SEM images showing the wrinkles on the surfaces of the GO membranes: (a) GO-1/25 $\mathrm{mL}$ and (b) GO-2/25 mL.

Figure S7. Instability the GO-2 membrane after immersion in the $\mathrm{D}_{2} \mathrm{O} / \mathrm{H}_{2} \mathrm{O}$ mixture after $10 \mathrm{~min}$.

Figure S8. Stability of the GO-1 and GO-2 membranes immersed in the $\mathrm{D}_{2} \mathrm{O} / \mathrm{H}_{2} \mathrm{O}$ mixture-10 mol\% $(\mathrm{pH}=6.8)$ after 1 week. 
Figure S9. Separation performances of the GO membranes with larger sheets subjected to repeated filtration cycles (a) overall filtration efficiency and (b) initial filtrate flux calculated for main filtration process (black), first repeated cycle (green), and second repeated cycle (red).

Figure S10. Effect of operating temperature on (a) initial filtrate flux and (b) overall rejection efficiency using commercial GO membranes.

Figure S11. Typical example of filtrate flux (green line) and rejection efficiency (blue line) changes during filtration. GO-1 membrane. Operating conditions: $\mathrm{T}=110^{\circ} \mathrm{C}, \mathrm{P}=1.2 \mathrm{bar}$.

Figure S12. XRD patterns from a GO-1 membrane. The calculated interlayer space was $8.46^{\circ} \mathrm{A}$ before filtration (black line) and $8.58^{\circ} \mathrm{A}$ after filtration (red line).

\section{Tables}

Table S1. O 1s XPS spectra results of GO-1 and GO-2 dispersions. 


\section{Preparation of membranes by filtering GO suspensions with $\mathrm{Cg}=1 \mathrm{mg} / \mathrm{mL}$}

We examined the filtration performance of membranes prepared by varying the volume of the filtered $\mathrm{GO}$ suspensions $(50,25,12.5 \mathrm{~mL})$ at constant $\mathrm{Cg}=1 \mathrm{mg} / \mathrm{mL}$. All $\mathrm{GO}-2$ membranes (i.e., GO with smaller lateral size) prepared in that way exhibited weak mechanical stability, which led to their failure during filtration. The thicknesses of the GO-1 membranes produced were 33, 16, and $8 \mu \mathrm{m}$, respectively. The two thickest membranes showed no water vapor permeation at $\Delta \mathrm{P}$ as high as 2.6 bar. The lack of permeation is attributed to random aggregation that occurs in thicker layered structures, as discussed in section 3. It has been shown that the increased hydrogen bonding density due to the higher number of stacked layers hinder water permeation [1]. However, from 0 to $1.5 \mathrm{bar}$, the thinner, $8 \mu \mathrm{m}$ thick, membrane allowed water vapor permeation to occur with the filtrate flux ranging from 1.38 to $10.26 \mathrm{LMH}$, respectively. It has been suggested water permeation increases in the thinner GO laminates due to an increase in the amount of nanopores created by defects or voids between individual GO platelets [2]. Our results show that adjustments to the filtration volume of GO suspensions alone are not sufficient to control membrane performance when high Cg concentrations are used. 

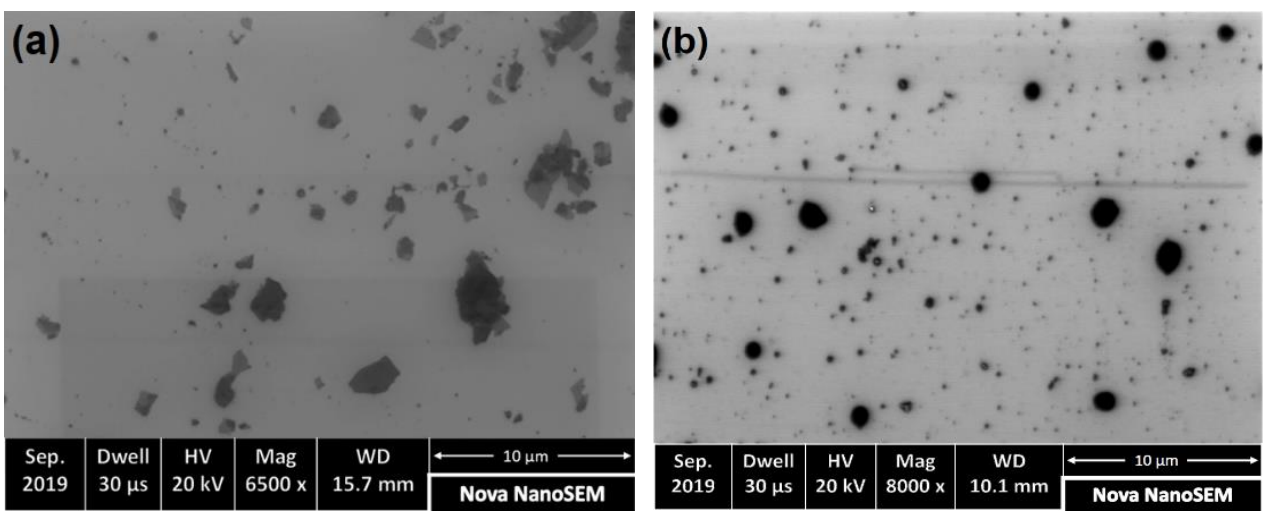

Figure S1. SEM images of nanoplatelets on a silicon substrate (a) GO-1 and (b) GO-2.

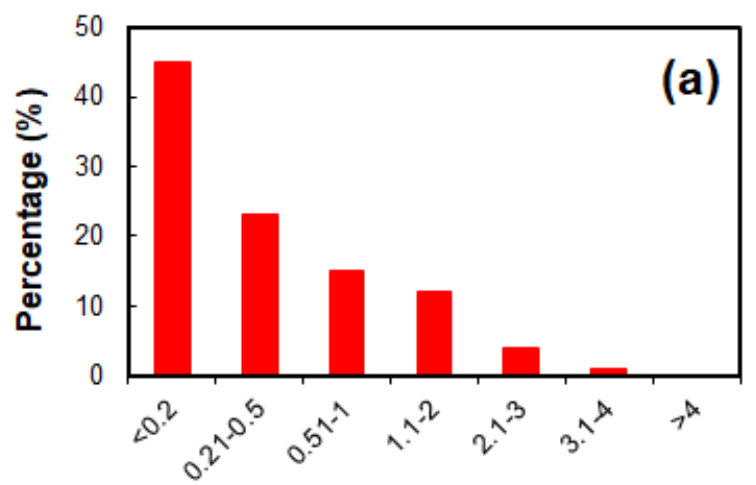

Flake size $(\mu \mathrm{m})$

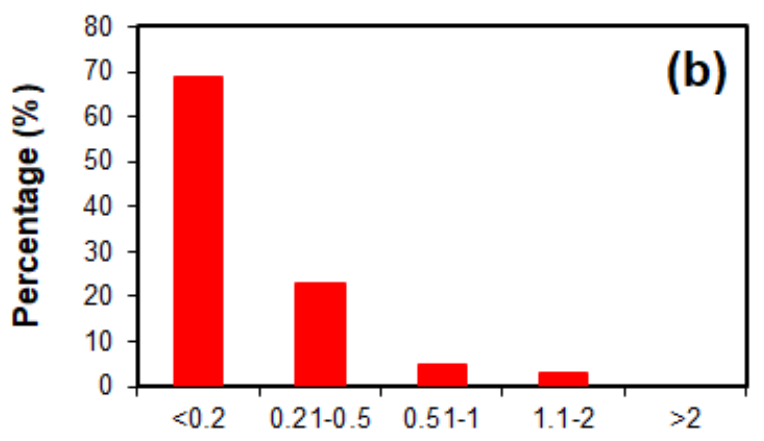

Flake size $(\mu \mathrm{m})$

Figure S2. Flake size distribution for (a) GO-1 and (b) GO-2 dispersion, respectively. 

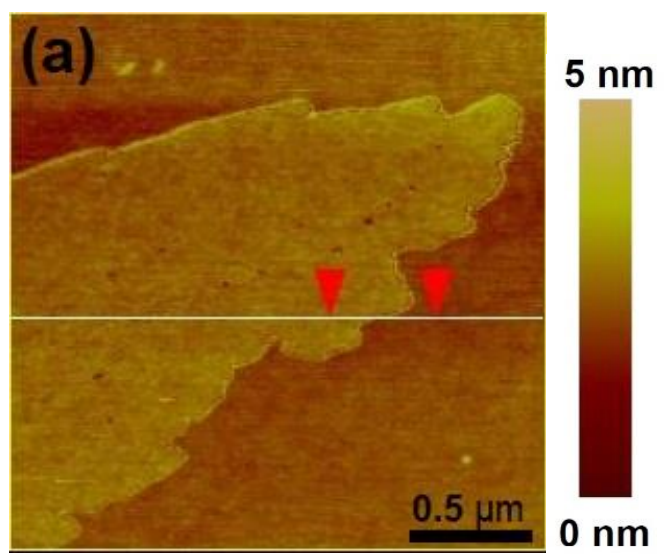

(b)
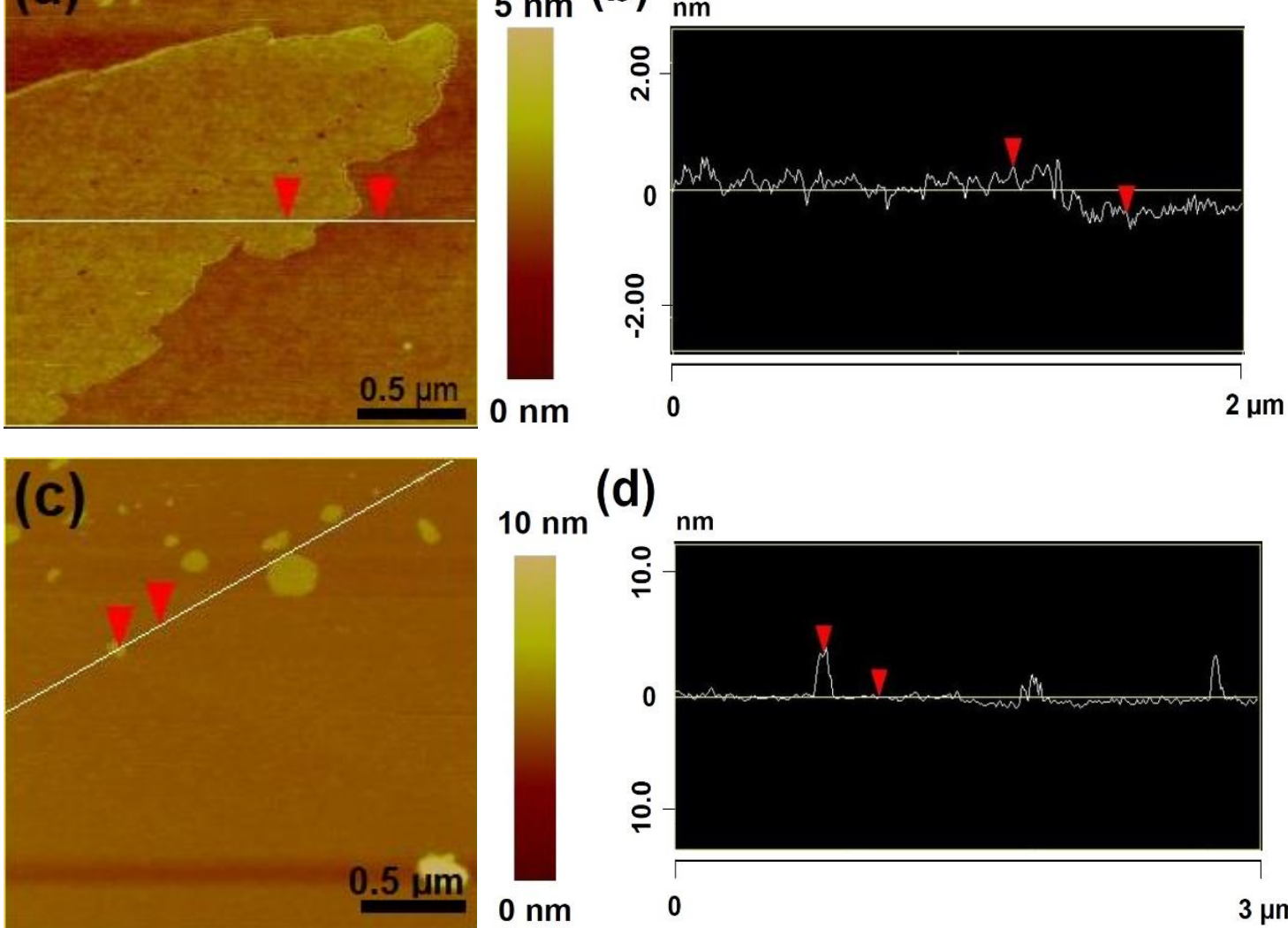

(d)

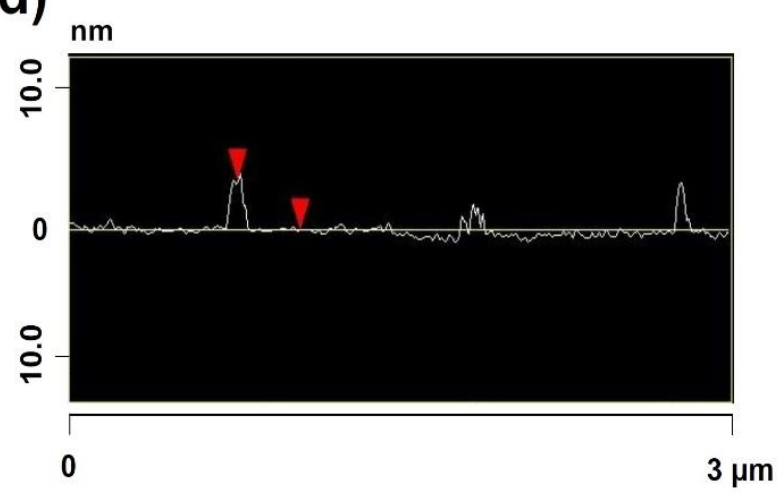

Figure S3. AFM images of (a, b) a typical GO-1 sheet platelet and its height profiles across the overlap (yellow line), (c, d) a typical GO-2 sheet platelet and its height profiles across the overlap (yellow line).

(a)

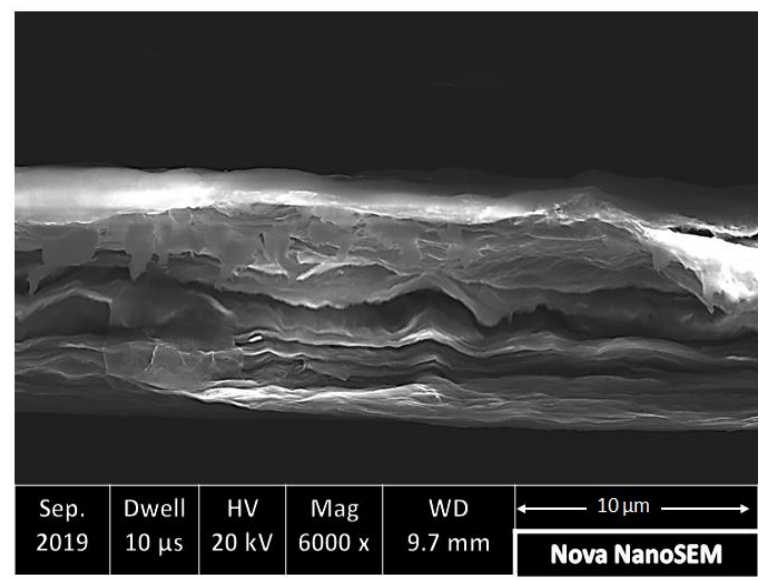

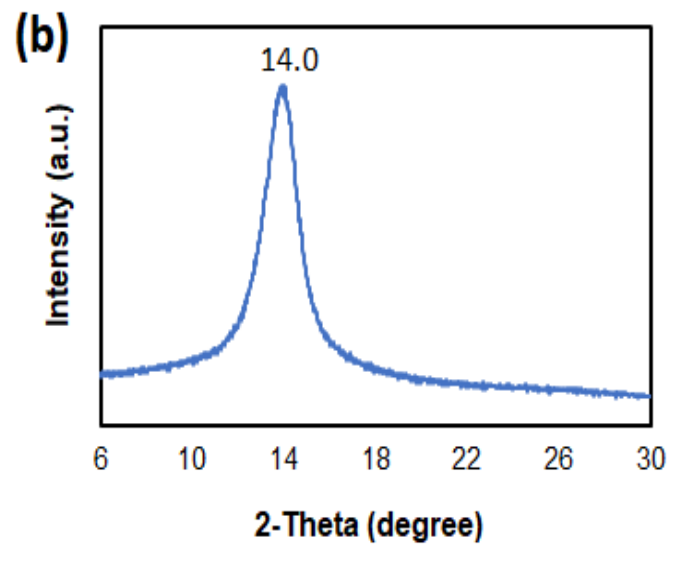

Figure S4. (a) SEM image showing the cross-section of a membrane prepared with larger lateral platelet size dispersion $(\mathrm{Vg}=25 \mathrm{~mL}$ and $\mathrm{Cg}=1 \mathrm{mg} / \mathrm{mL})$ and (b) XRD pattern for the prepared $\mathrm{GO}$ membrane with interlayer space of $7.33 \AA$. 


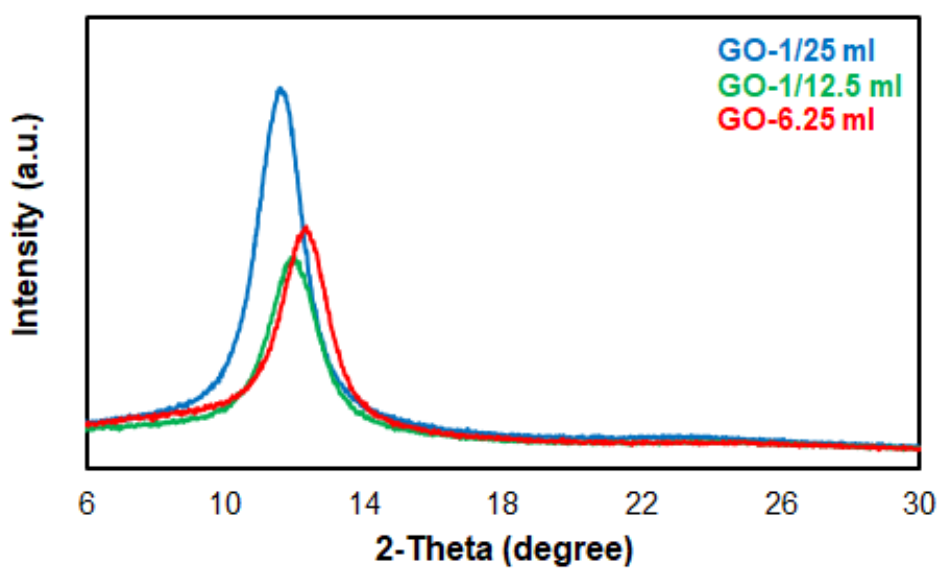

Figure S5. XRD patterns for the GO membranes prepared with $\mathrm{Cg}=0.55 \mathrm{mg} / \mathrm{mL}$.
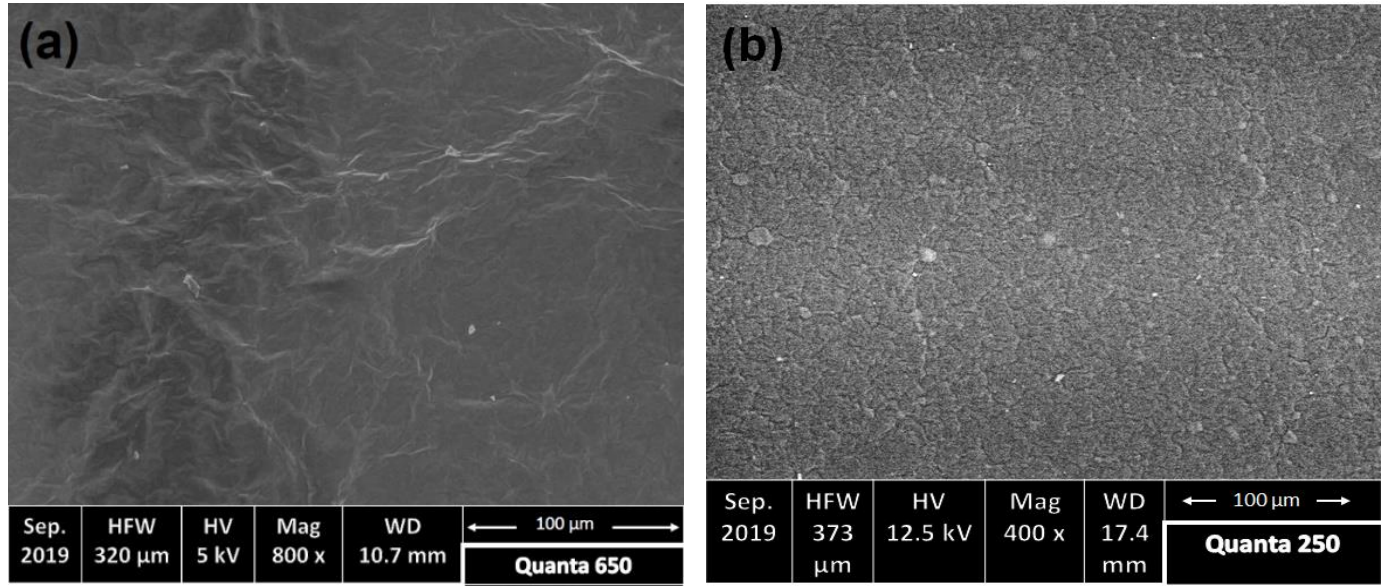

Figure S6. SEM images showing the wrinkles on the surface of the GO membranes: (a) GO-1/25 $\mathrm{mL}$ and (b) GO-2/25 mL. 


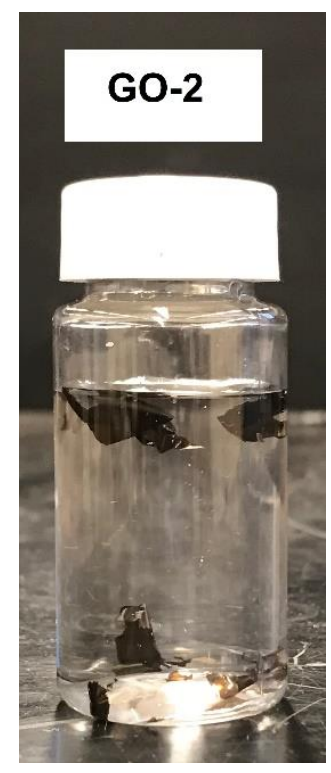

Figure S7. Instability of the GO-2 membrane after immersion in the $\mathrm{D}_{2} \mathrm{O} / \mathrm{H}_{2} \mathrm{O}$ mixture after 10 $\min$.

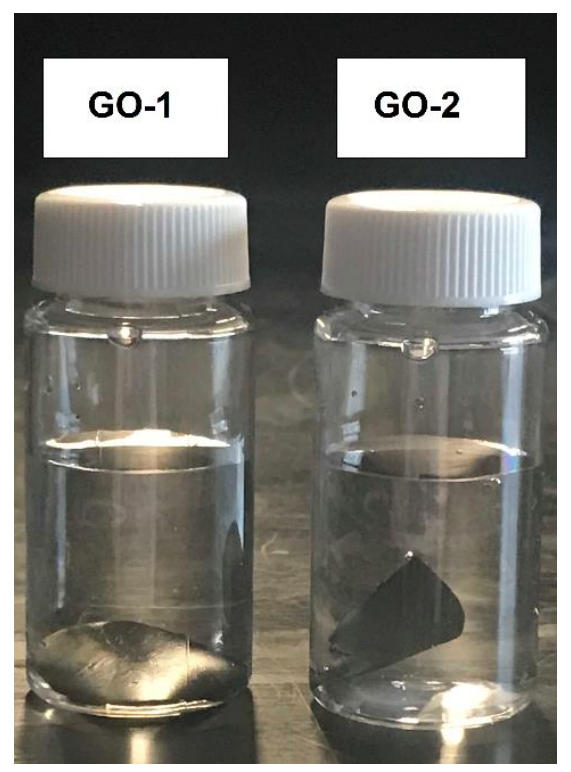

Figure S8. Stability of the GO-1 and GO-2 membranes immersed in the $\mathrm{D}_{2} \mathrm{O} / \mathrm{H}_{2} \mathrm{O}$ mixture-10 mol\% $(\mathrm{pH}=6.8)$ after 1 week. 

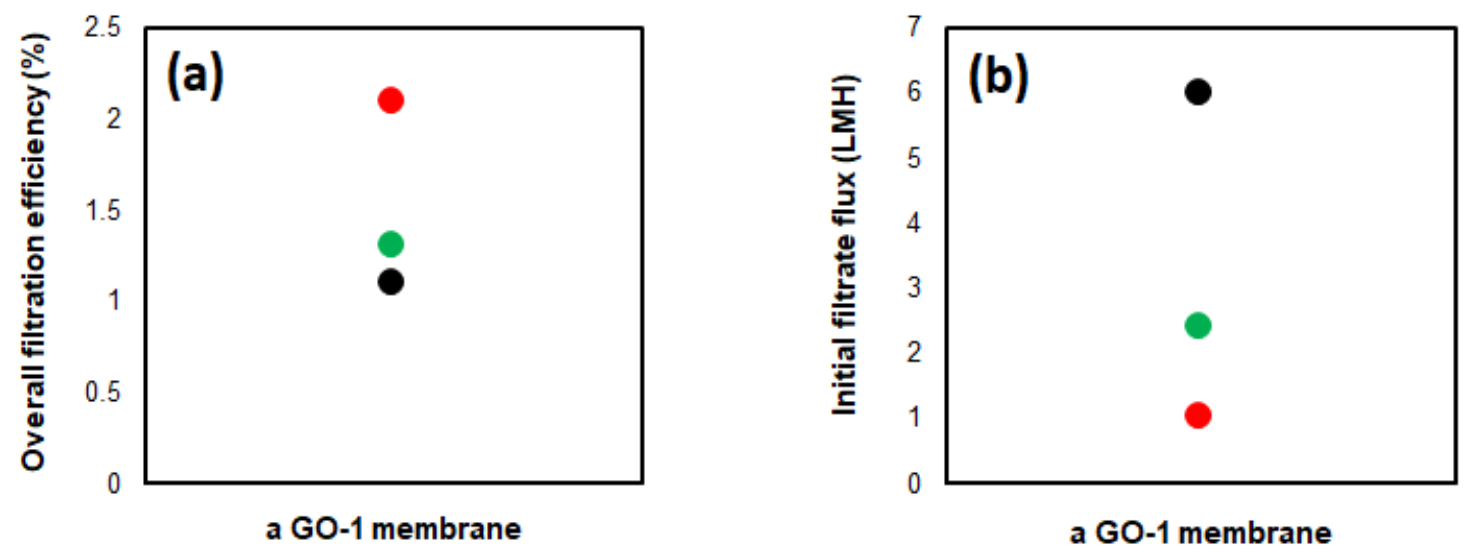

Figure S9. Separation performances of GO membranes with larger sheets subjected to repeated filtration cycles (a) overall filtration efficiency and (b) initial filtrate flux calculated for main filtration experiment (black), first repeated cycle (green), and second repeated cycle (red).
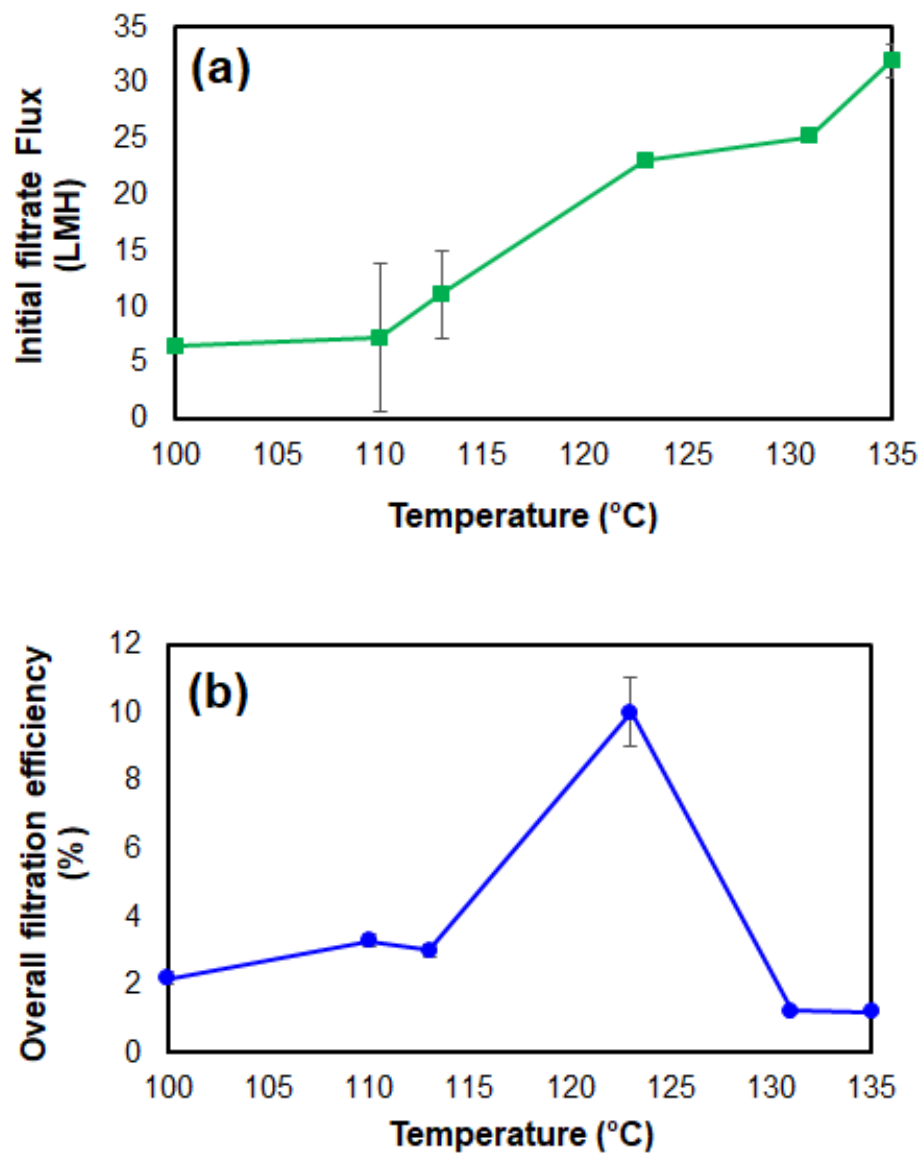

Figure S10. Effect of operating temperature on (a) initial filtrate flux and (b) overall rejection efficiency using commercial GO membranes. 


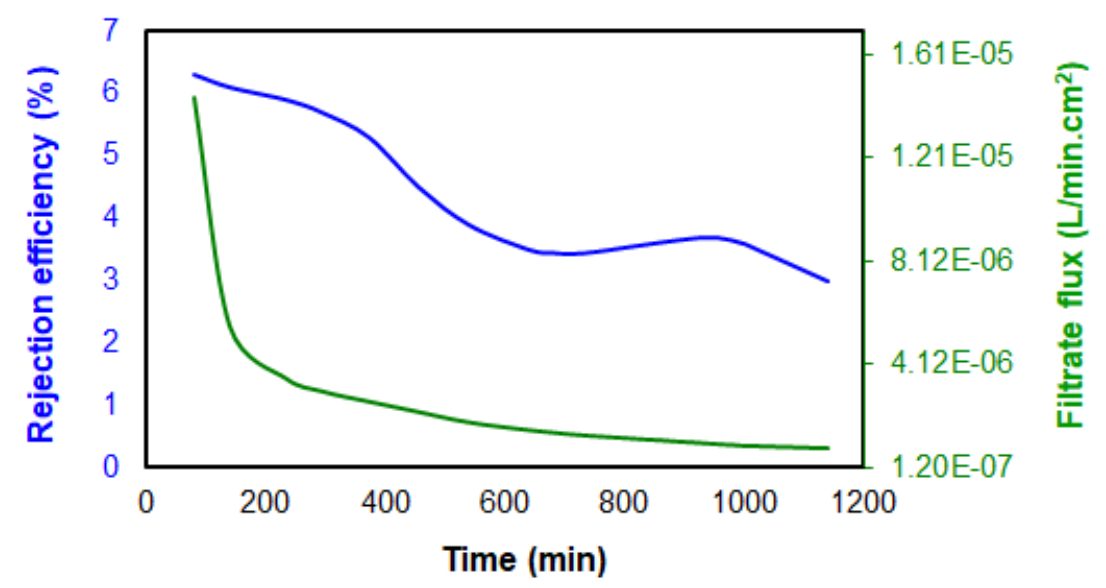

Figure S11. Typical example of filtrate flux (green line) and rejection efficiency (blue line) changes during filtration. GO- 1 membrane. Operating condition: $\mathrm{T}=110{ }^{\circ} \mathrm{C}, \mathrm{P}=1.2 \mathrm{bar}$.

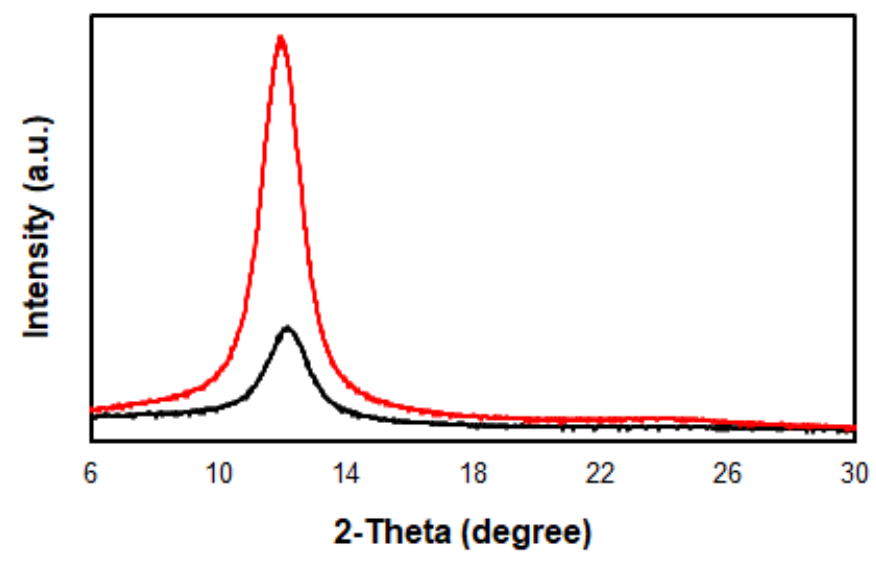

Figure S12. XRD patterns from a GO-1 membrane. The calculated interlayer space was $8.46^{\circ} \mathrm{A}$ before filtration (black line) and $8.58^{\circ} \mathrm{A}$ after filtration (red line). 
Table S1. O 1s XPS spectra results of GO-1 and GO-2 dispersions.

\begin{tabular}{|c|c|c|}
\hline $\begin{array}{c}\text { Oxygenated } \\
\text { groups }\end{array}$ & $\begin{array}{c}\text { Atomic concentration } \\
\text { \%At Conc } \\
\text { (GO-1) }\end{array}$ & $\begin{array}{c}\text { Atomic concentration } \\
\text { \%At Conc } \\
\text { (GO-2) }\end{array}$ \\
\hline $\mathrm{O} 1 \mathrm{~s}, \mathrm{C}-\mathrm{O}, \mathrm{O}-\mathrm{C}=\mathrm{O}$ & 27.07 & 27.14 \\
\hline $\mathrm{O} 1 \mathrm{~s}, \mathrm{C}=\mathrm{O}$ & 2.14 & 2.95 \\
\hline
\end{tabular}

* Atomic concentration of each peak is calculated as Normalized Area * 100 / Sum of Normalized Areas.

\section{References:}

[1] Chong, J. Y.; Wang, B.; Mattevi, C.; Li, K. Dynamic microstructure of graphene oxide membranes and the permeation flux. J. Membr. Sci. 2018, 549, 385-392

[2] Coleman, M.; Tang, X. Diffusive transport of two charge equivalent and structurally similar ruthenium complex ions through graphene oxide membranes. Nano. Res. 2015, 8, 1128-1138. 